\title{
A Systematic Review of Augmented Reality Applications in Language Learning
}

\author{
https://doi.org/10.3991/ijet.v16i10.17273
}

\author{
Siti Norzaimalina Abd Majid ( $\left.{ }^{\bowtie}\right)$, Abdul Rahim Salam \\ Universiti Teknologi Malaysia, Johor Bahru, Malaysia \\ sitinorzaimalina@gmail.com
}

\begin{abstract}
Augmented Reality (AR) is one of the emerging technologies gradually venturing into the education field. Although AR is strongly linked to subjects related to Science, Mathematics, and Technology in schools and tertiary education, there is no mention of AR in non-technical subjects, such as language. Thus, this study aims to discover the AR application trends in language learning and the language skills prevalent in AR usage. In this systematic literature review, AR-related research in language learning began in 2016 and has continued to be on the rise. Furthermore, the preferred language skills used with AR technology required lower cognitive levels, such as identifying words, understanding meanings and spelling, and pronouncing words. Based on the gap indicating the rare usage of AR for more complex and critical language skills, such as reading and writing, this study hopes to enlighten the researchers, educators, and application developers to focus on developing AR applications for languages other than English, incorporate higher-order learning outcomes in the language learning activities, and pursue qualitative investigations.
\end{abstract}

Keywords-Augmented Reality, language learning, technology in education, systematic literature review

\section{Introduction}

The rapid scientific and technological developments have changed how people live with technology in the 21st century. Furthermore, the growth of AR, Virtual Reality (VR), and mixed-reality technologies are expected to increase in the next few years. In a recent research by the International Data Corporation, as cited in [1] $70 \%$ of the companies will test immersive technologies for commercial and consumer use by 2022 , with about $25 \%$ of expected product deployment. Besides, the recent COVID19 pandemic has increased the number of immersive technology consumers as a new means of collaborating with colleagues and self-entertainment [1].

Other sectors were also affected by the dynamism in technological transformations. As such, one of the fields that could benefit from this technology is the educational field. New learning approaches were pursued with technological assistance to motivate students' learning, strengthen students' understanding, and promote collaboration and engagement. Many technologies were utilised in education to support learning 
and teaching. Therefore, researchers and educators conducted prolific technologyrelated studies to enhance teaching and learning in various ways, such as mobile learning [2-4], online learning [5-7], social media [8-10], digital game [11-13], and augmented/virtual reality [14-16]. Due to the multiple technologies available in education, this paper would only focus on one emerging technology, which is AR.

\section{Background}

\subsection{The AR technology}

One of the emerging technologies garnering interest in educational settings is AR. To begin with, AR is a technology enabling users to view computer-generated objects overlayed with reality [17] and the live integration of virtual objects or digital and virtual information (graphics, sounds, and haptic feedback) in an authentic environment. The nature of AR permits user interaction with virtual and real objects in the same space, thus creating a new user learning experience [18].

These objects simultaneously co-existed with real-life objects using cameras on mobile or head-mounted devices [17]. According to [17], the three main AR characteristics include: (1) the combination of real and virtual worlds (2) real-time interactions, and (3) 3-D registrations of virtual or computer-generated objects. The cameras in mobile and head-mounted devices served as a means for augmenting relevant information by identifying an AR application's trigger points or markers in reality. As such, AR's capabilities offered many promising future applications.

The AR tools were accessible to major companies for creative visualisations and training purposes around the 1990s [19]. Additionally, the tools were basic and computer-based. Nevertheless, with the initial popularisation of mobile applications around 2008, a few AR applications were available to users in the market. The subsequent increase in demand resulted in the emergence of AR tools, primarily designed for entertainment and marketing purposes. Moreover, Johnson, et al. [19] predicted that AR would venture into other sectors, such as education, as a result of the technology's gradual maturity and development. However, the AR's adoption and simplification in teaching and learning, particularly in higher education, would take approximately two to three years [19].

With technological advancement, AR technology was widely used with computers and mobile devices [20]. with a more consumer-oriented, cost-effective, accessible, and affordable approach to users. Past studies on AR usage in education focused more on Science, Mathematics, and technical subjects, in line with the subjects' fact-based nature requiring models to visualise abstract concepts $[20,21]$. Although several studies have discussed these subject areas, not many highlighted the language learning field. Therefore, this paper's scope focused on AR in language learning. 


\subsection{The AR technology in language learning}

The integration of AR technology in education has shown many positive impacts on language learning. For example, studies showed that AR technology offered many advantages in language learning. Also, Bacca, et al. [21] reported that AR improved learning achievements and boosted motivation, engagement, and collaboration among learners. Learners' comprehension and long-term memory retention could also be enhanced and developed [22]. Similarly, Diegmann, et al. [23] stated that AR could improve learners' cognitive and spatial level abilities, creativity, attention, and concentration. Saidin, et al. [24] also revealed that AR features could improve learners' visualisation skills.

However, some researchers drew certain limitations on AR utilisation in language learning. Radu [22] indicated attention diversion, difficulty in using AR, ineffective classroom integration, and the inability to cater to high-achieving students. Furthermore, Bacca, et al. [21] stated that the most reported limitations involved maintaining superimposed information, paying excessive attention to virtual information, and considering AR as intrusive technology. In general, the most reported disadvantage concerned technical issues, specifically design flaws in the user interface [25-28] such as inconsistent responses in AR applications [25, 28], unexpected programme exits, delayed responses [27, 29] and inaccuracies of sensor detection [28]. As the research on AR integration in education is still developing, the resulting limitations could be overcome by fully exploring potential AR technologies with an adequate timeline for technological stability and maturity.

\subsection{Research questions}

A considerable number of systematic review research focused on the broad sense of AR utilisation in education [20,21, 30,31]. Although AR research reviews for educational purposes were discussed within the general trends, AR applications across disciplines, the challenges and advantages of AR utilisation, learning outcomes, and AR effectiveness, a systematic review of AR applications, specifically in language learning, remains lacking.

Hence, the motivation to conduct this systematic review paper was in discovering where language learning situates in the field of AR and identifying the integration of common skills with AR in language learning. The investigation of AR utilisation in language learning proved essential in facilitating researchers to uncover potential learning in the study area and determining the worthiness of the research field [20]. This review could suggest the practical areas in which AR could be used as a language-learning tool. Therefore, the following research questions were addressed in this study: 
1. What is the distribution over time of the articles examining AR utilisation in language learning?

2. What are the learner types commonly selected for the research?

3. What are the AR technology types and displayed devices used in language learning?

4. What type of research design is applied to examine AR use in language learning?

5. What are the learning theories applied to examine AR utilisation in language learning?

6. What are the language skills frequently used with AR technology?

\section{Method}

Systematic reviews have been used as a scientific method to gain a comprehensive insight into a specific research domain and aided future researchers in bridging the research gap and identifying the trends in the current study. Therefore, a systematic review attempted to organise the relevant data matching pre-determined eligibility criteria in answering a specific research question [32].

The ways of review reporting were governed by the principles of the Preferred Reporting Items for Systematic Reviews and Meta-Analyses (PRISMA) statement [32] where researchers explained the eligibility criteria, information sources, datacollection processes, data items, and synthesis of the results. For example, this study reviewed publications indexed in recognised and reputed journals to obtain an overview of AR utilisation, specifically in learner types, the AR technology used, research designs, the theories underpinning AR applications in language learning, and language skills.

\subsection{Selection of criteria}

The scientific articles published in journals indexed in the Social Sciences Citation Index (SSCI) and SCOPUS databases on AR utilisation were obtained for this review. The two databases are widely known as reputable and highly-cited journals in the academic world [33] and are the main resources of many review studies. Additionally, the field tags of indexed articles were easily accessible and customisable based on the researcher's needs [34].

For SSCI- indexed articles, the Web of Science (WOS) was the access point in using advanced search functions, with the input search terms 'augmented reality', 'augmenting reality', and 'mixed-reality'. Also, the parameters were set, whereby: language was limited to English; document types were limited to articles and proceeding papers, and the time span was from 2010 to 2020. A duration of 10 years was deemed adequate to observe the AR trends in language learning and the contemporary use of AR. As such, the search yielded 70 results.

Advanced search functions were also used in the Scopus database, with the same query as the WOS database, except for a slight difference from WOS. For example, there was no 'Topic' function, but 'Topic' in WOS was equivalent to the 'Title, Abstract, and Keyword' function in SCOPUS. However, 'Keyword' in this review was not included in the query string to bring more validity to the results [33]. Similar pa- 
rameters were applied, whereby: language was limited to English; document types were limited to articles and proceeding papers, and the time span was from 2010 to 2020. The search yielded 66 results, with the last search conducted on 25 April 2020. The approach to the paper selection is shown in Figure 1.
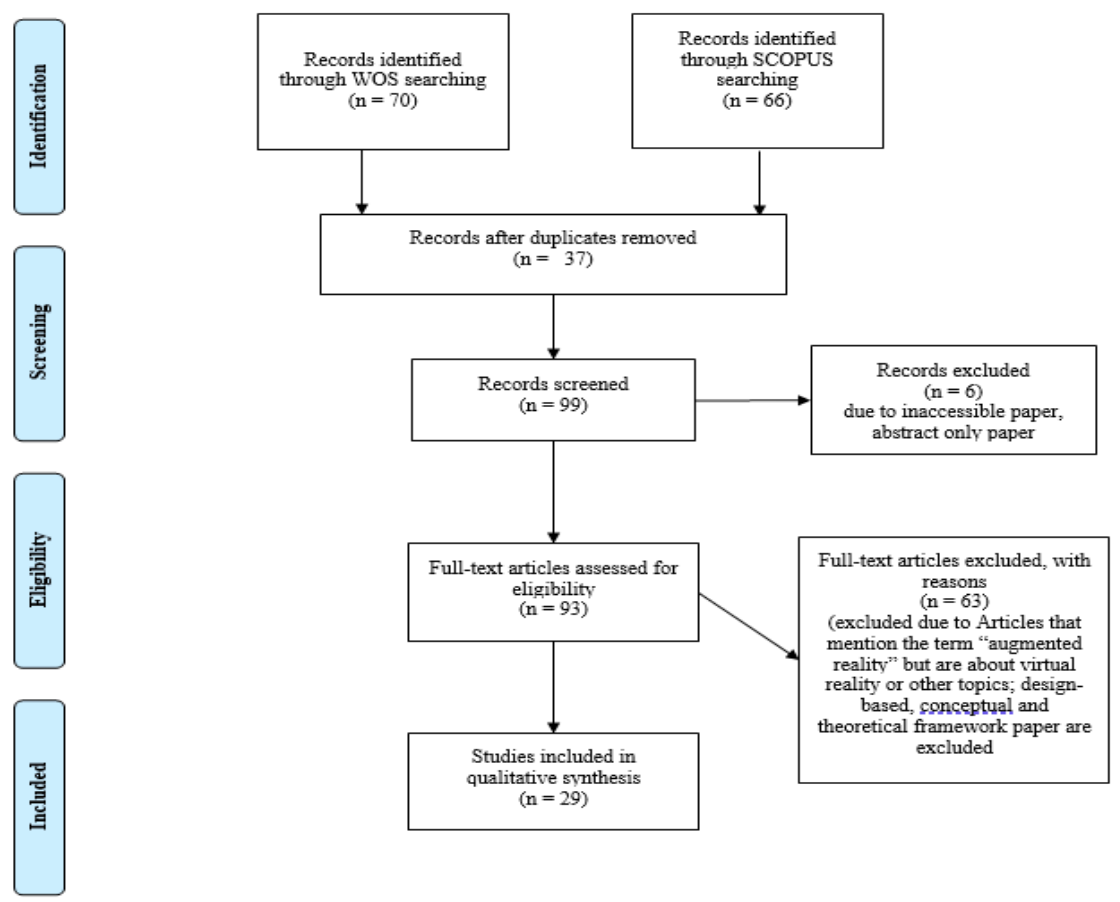

Fig. 1. The systematic review process

A set of inclusion and exclusion criteria were adopted during the systematic review process (refer to Table 1). Following the criteria applications, 29 articles were found to be relevant to the study's purpose. 
Table 1. Inclusion and exclusion criteria

\begin{tabular}{|c|c|}
\hline Inclusion & Exclusion \\
\hline $\begin{array}{l}\text { Research must include empirical study. } \\
\text { Must involve AR as primary or additional } \\
\text { component in learning language. } \\
\text { The articles present result of the application of } \\
\text { AR for language learning and the instruments } \\
\text { used in the evaluation of AR involved. } \\
\text { Types of documents included journal articles, } \\
\text { and conference proceedings, written in English } \\
\text { The target language can be either in English or } \\
\text { other languages. }\end{array}$ & $\begin{array}{l}\text { Articles do not address the actual application of AR in } \\
\text { language learning. } \\
\text { Symposium, editorial writings, meeting abstracts, book, } \\
\text { book chapters, master's theses, and PhD these, biographical } \\
\text { items are excluded. } \\
\text { Articles that mention the term "augmented reality" but are } \\
\text { about virtual reality or other topics. } \\
\text { Design of AR app, conceptual and theoretical framework } \\
\text { are excluded. } \\
\text { Abstract only paper } \\
\text { Design-based research } \\
\text { The study does not present the results clearly and the } \\
\text { instruments used in the evaluation of AR. }\end{array}$ \\
\hline
\end{tabular}

\subsection{Conducting the review}

All the 93 articles were downloaded as full texts on computers. Two researchers were involved, with the first author conducting the initial review and the second author (a senior researcher) conducting the final review. Each article was examined and read thoroughly to determine the inclusion eligibility in the final review. The inclusion and exclusion criteria presented in Table 1 were applied during this stage. Also, the articles were selected during the study's discussion on AR usage in learning language and the effects on learners when learning language skills.

Nonetheless, the articles mentioning AR elaborated on VR instead, with no discussions on the effects of using AR, design-based studies, conceptual and theoretical frameworks, and abstract-only papers, were omitted. The relevant information related to research questions were organised through Nvivo 12 Plus and Microsoft Excel. Also, the data collected from the articles were determined using the qualitative content analysis method, which allowed for more systematic and objective categorisations of qualitative data [20].

All the articles were analysed, synthesised, and presented in relevant diagrams based on the outlined research questions. Some of the information was derived from the articles with word searches to find keywords, such as paper distribution according to time, learner types, and research designs. However, other areas, including AR types, AR display devices, the theory underpinning the study, and language skills required more detailed and careful analysis.

\subsection{Categories}

The year of the journal publications ranged from 2010 to 2020 in this review. The 10-year span was adequate to observe the research trends using AR, specifically in the direction of language learning concerning AR technology. Learner types were divided into five categories: pre-school or kindergarten, grade 1 to 6 (primary school), grade 7 and 8 (secondary school), grade 9 to 12 (high school), and college or tertiary students. For the AR trigger types, the three categories include marked, marker-less, and loca- 
tion or GPS-based. For the AR display devices, the sub-categories were divided into mobile devices (smartphones and iPods), tablets, desktops or webcam-based devices, projectors, head-mounted devices (HoloLens), and other unspecified devices. For the research design, three categories were selected: quantitative, qualitative, and mixedmethod [35]. Learning theories and language skills categories were based on the paper and not pre-determined. The findings of the study are summarised in the next section.

\section{$4 \quad$ Findings}

\subsection{What is the distribution over time examining AR usage in language learning?}

Based on the analysis, the number of articles published on AR usage in language learning gradually increased in 2016, despite a slight dip in 2017 (see Figure 2), and reached a peak in 2019. Johnson, et al. [19] forecasted in 2010 that the upcoming years (2011-2013) predicted a strong potential in AR applications for educational purposes compared to the previous focus on entertainment and marketing. However, $47 \%$ of the studies using AR in education were applied in the field of 'Science' [21]. The field of Humanities and Arts, which also comprised of language, merely covered approximately $22 \%$ of the studies. Hence, this review supported the previous study concerning the lack of research reported on AR usage in language learning until 2015.

However, companies such as Google were a precursor for AR and VR to become popular technologies in 2015, followed by Snapchat as the first social media platform to successfully integrate AR user features in the same year [36]. The platforms may also contribute to the increased interest in AR usage regarding language learning, consequently increasing the publication of articles from 2015 onwards. Other reasons for the increase include high AR availability, affordability, and easier operability [37]. Thus, more AR-related research in language learning was likely to increase in the future.

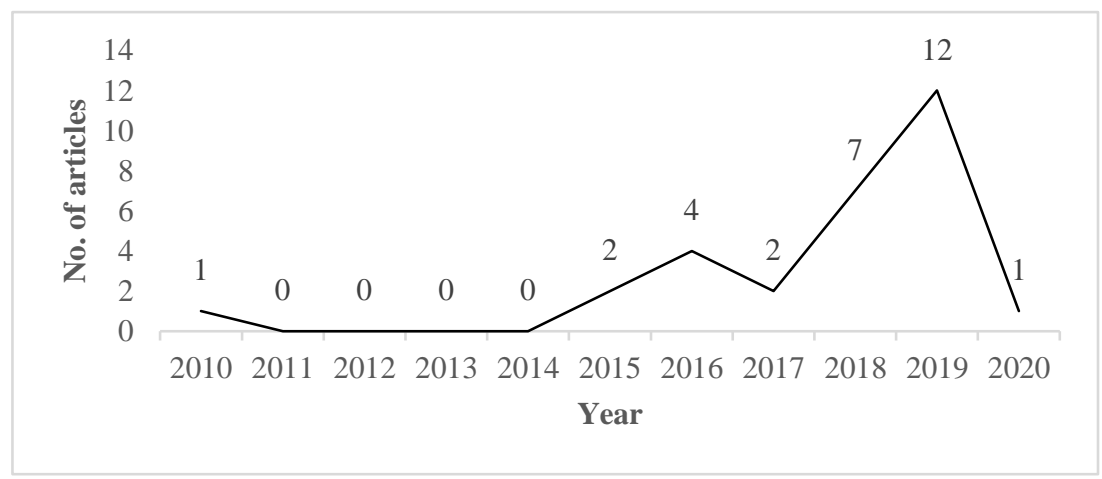

Fig. 2. Number of articles published by year 


\subsection{What are the learner types commonly selected for the research?}

From the 29 study samples, 12 studies (41.4\%) selected college and university students as the study participants. The second highest was primary school students (37.9\%), whereas the remaining studies involved kindergarteners (17.2\%) and high school students (3.5\%). None of the research in this study of AR in language learning was conducted on middle school students. The large proportion of college and university students as study participants corresponded to previous studies $[21,38]$ potentially due to the accessibility of mobile devices, [39], readily available samples [38], and the ability to give detailed and constructive feedback on the use of AR applications. Most of the AR applications from the study were prototypes, hence requiring feedback on the effectiveness and usability of the applications from matured language learners.

\subsection{What are the AR technology types and display devices used in language learning?}

This review categorised AR into three types: marker-based, markerless, and location-based [40]. This study revealed that the marker-based type was the most common AR type used in language learning, with 19 out of 29 studies using a marker-based type. Additionally, nine of the studies used location-based AR, whereby GPS location was used to explore and learn the geographical-based content through real-time GPSpositioning. For location-based AR, most of the reported studies embedded gamification or game-based principles in language activity. Only one study used a marker-less type. Also, 26 of the studies used prototypes of AR applications developed by the researchers, while three other studies used existing AR applications in the market.

A display type must be used to view virtual objects or information augmented in real life. As such, a few display types were used (see Table 2), but the types were not limited to one display device for one study. Four of the studies utilised two devices simultaneously: three studies used computer desktops and projectors and one study used computer desktops with HoloLens. Also, each device type was counted as one. Due to the occurrence of multiple devices, the total number of devices was more than the total number of studies. Only two of the studies mentioned generic device terms, which were electronic devices and devices with installed applications.

Table 2. Types of AR Display Devices

\begin{tabular}{|l|c|}
\hline \multicolumn{1}{|c|}{ AR Display Devices } & Total \\
\hline Mobile Devices (Smartphones/iPod) & 14 \\
\hline Tablet & 8 \\
\hline Desktop/Webcam-based Devices & 7 \\
\hline Projector & 3 \\
\hline Head-Mounted Device/HoloLens & 1 \\
\hline Unspecified & 2 \\
\hline
\end{tabular}




\subsection{What type of research designs and data collection methods are applied to examine $A R$ usage in language learning?}

The analysis indicated mixed-method as the most frequent research design used, parallel to [21]'s finding, comprising of 17 studies, followed by quantitative (eight studies) and qualitative (four studies) research designs. For the mixed-method design, the studies were generally explanatory and sequential, as the studies began with the quantitative method, followed by the qualitative method. Although many studies did not explicitly describe the use of a mixed-method, the analysis indicated that the studies executed quantitative and qualitative data collection. Therefore, this review identified the studies as a mixed-method design despite the absence of the 'mixed-method' term.

Furthermore, the data collection methods used were categorised parallelly to a study conducted by Maas and Hughes [41] in which a variety of data collection methods were used from the 29 selected studies within this review. Based on Figure 3, questionnaires were widely used as a data collection method (20 studies), followed by pre and post-tests (15), interviews (11), observations (7), field notes (6), videos (6), and focus group discussions (5). On another note, evaluation forms, gameplay data, and reflection reports were implemented in two studies, whereas audio, documents, and pre-tests were applied in one study.

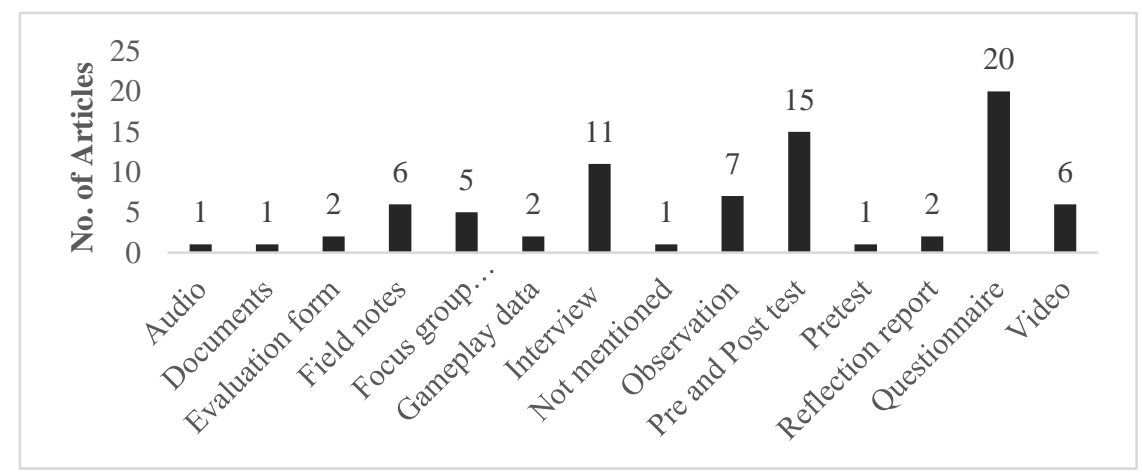

Fig. 3. Data collection methods

\subsection{What are the learning theories applied to examine AR usage in language learning?}

The use of theory in empirical research proved substantial to describe, explain, and predict the phenomena in a study [42]. The research findings within a theoretical framework facilitated in 'making sense' of the data (May 1998, as cited in Hew, et al. [42]. Thus, the learning or educational theories supporting AR in language learning were identified in this paper. The keyword 'theory' was used to initially locate the theory stated in the paper. When no hits were identified, each paper was thoroughly examined and scrutinised for AR-related theories or concepts in language learning. 
In this study, 17 of the theories or concepts were only mentioned once: collaborative learning, cognitive load, cognitive theory, constructivism theory, content and language integrated learning, context-conscious ubiquitous learning, contextual learning, drones, dual coding theory, interactional approach, learning style, manipulative theory, mixed reality, mobile learning, mobile-placed learning, self-determination theory, and self-directed learning. From the observation, eight studies did not mention any theories underpinning the use of AR applications. Similarly, the theory related to game-based learning or gamification was mentioned in eight studies. Other theories mentioned in the studies are depicted in Table 3. On another note, ten of the studies mentioned one theory, eight did not state any theory, four explained two theories, two explained five theories, and only one study mentioned three, four, six, seven, or eight theories.

Table 3. Theories/concepts mentioned in the studies

\begin{tabular}{|l|c|}
\hline \multicolumn{1}{|c|}{ Theories/Concepts } & Total \\
\hline Collaborative dialogue & 2 \\
\hline Computer assisted language learning & 3 \\
\hline Embodied learning & 3 \\
\hline Flow theory & 2 \\
\hline Game-based learning/gamification & 8 \\
\hline Cognitive theory of multimedia learning & 3 \\
\hline Mobile assisted language learning & 2 \\
\hline Multimedia learning & 3 \\
\hline Not mentioned & 8 \\
\hline Place-based learning & 3 \\
\hline Situated learning & 5 \\
\hline Sociocultural theory & 2 \\
\hline Task-based learning & 2 \\
\hline Others & 17 \\
\hline
\end{tabular}

\subsection{What are the language skills frequently used in AR technology?}

Language skills were generally divided into four major skills: reading, writing, speaking, and listening. For example, the sub-skills derived from the major skills include vocabulary, orthography, spelling, and pronunciation. This review portrayed studies assessing multiple skills simultaneously. Hence, the total number of skills exceeded the number of studies. It was also observed from the findings that the vocabulary sub-skill was commonly used in AR technology, with 14 instances, followed by orthography (spelling and character recognition), with eight instances, and pronunciation, with five instances. Another skill that was not language-specific but assessed four times in the study was collaborative learning.

Furthermore, communication or speaking skills and grammar were evaluated in three of the studies. Although there were three studies using AR applications, the language areas were integrated, as the learners used language in daily conversations and demonstrated the skills in an authentic setting. Besides, the use of AR in the reading skill was observed in two studies, which focused on reading given words and 
understanding the meaning. Other skills included writing and listening, as observed in one study. Global skills were also identified in one study on AR usage, which was linguistic awareness and cultural understanding.

Moreover, this paper discovered 21 studies using AR applications to aid learners in learning English, while four studies involved learning Chinese with the assistance of AR applications. The remaining four languages were French, Japanese, Quechea, and Basque, with the frequency of one study each. Hence, it was worthy to note that the possibility of other languages using AR applications in language learning without English translations represented a study limitation.

\section{Discussion}

Based on the findings, there is an increasing demand for research related to AR usage in language learning from 2010 to 2020. Although the use of AR in language learning is still new, the usage has increased from 2016 onwards. Despite the rising trend, the sample choice was more common in young children and university students. One of the possible reasons why young children were preferred in these studies could be that AR offered strong visualisation features important for children at a concrete operational stage [20].

Since the language type or skill commonly used with AR technology was a lowerorder cognitive skill (remembering, recognising letters, understanding meanings, pronunciation), primary school students were the most suitable participants based on the on-going development of basic language skills. Besides, many language teachers still believed that repetition and drilling approaches were crucial to strengthen linguistic foundations [43] and improve knowledge retention [44]. Moreover, previous studies $[21,30,37]$ revealed that undergraduate students were the most studied sample in the educational technology field. Based on research conducted by the EDUCAUSE Centre for Analysis and Research, 95\% of undergraduate students owned smartphones. Since most of the AR technologies used realistic mobile device platforms [45] mobile learning studies have also grown due to the increase in mobile device ownership [19].

Regarding AR types, most of the studies utilised marker-based types. In Arici, et al. [46], marker-based materials on paper were preferred, as these materials were simple to create and operate, with less complexity in development, as developers could use existing AR Software Developer Kits (SDK) to develop marker-based AR applications [45]. With various AR platforms in the market, such as Adobe Aero and ARize, people could develop personal AR applications. The tracking process of markers was also more reliable and accurate than the marker-less type [21, 45].

Concerning the research design, most of the studies applied a mixed-method design, followed by quantitative and qualitative designs. Based on the findings, mixed methods were favoured, possibly because new AR application prototypes were developed in the studies. In designing a new technological prototype, it was prevalent to question the participants' responses on the perceived usefulness and ease of use concerning the product, and the attitude and behavioural intention towards the product 
[47], as earlier studies suggested a need to apply mixed methods in AR-related studies [40] to counter the pervasiveness of quantitative studies. However, qualitative data analyses in the mixed-method research were mostly descriptive analyses of how the activities were perceived by learners (learner experience, perceived enjoyment, attitude, and motivation). These basic descriptions aided in understanding the experience holistically, although the descriptions did not elaborate on the variables contributing to the experience.

From this analysis, a more in-depth investigation was required to cover aspects involving knowledge gain, cognitive processes, and collaboration mediated by AR technology. Besides, 27 studies in this review developed a new AR application, specifically for the target group. Only two studies used the readily available AR applications, which were Pokémon Go and ChronoOps (in ARIS application). With the gradually increasing number of AR applications related to language learning, future researchers may embark on assessing the practicality of using this application in language classrooms and discuss the reinforcement of language skills.

The use of theory is imperative for knowledge development and in understanding a certain phenomenon [42]. For example, theories can inform and explain how and why a particular learning approach is suitable for certain learner groups. Based on Table 3, although eight of the studies did not mention any theories, the development and implementation of AR applications were described. The common theories used in this review concerned game-based learning and gamification, possibly due to the early adoption of AR focused on entertainment and gaming industries [19]. Thus, it makes sense that AR technology in education embedded gamification or game-based learning principles. The analysis revealed few studies mentioning the theories, but the theories did not link to the method, data collection, or analysis in the discussion. However, most of the articles utilised theories to conceptualise the research objectives, collect and analyse data, and discuss the findings.

Additionally, [42] suggested that many educational technology-based studies emphasised theoretical exemplification through theoretical insights or constructs to discuss the relationship between theory and data. Moreover, the theories in educational technology-based research generally revolved around the same theory. Therefore, there is a need to develop more theories, specifically in education, and contribute to theoretical advancement. The findings also reported vocabulary acquisition to be the preferred learning outcome in AR usage concerning learning language, as the acquisition proved to be an essential skill to be mastered before advancing to more complex components. Studies indicated that vocabulary mastery significantly contributed to users' language proficiency [43, 48]. As such, vocabulary is a prerequisite for learners to understand sentences, paragraphs, and essays.

Apart from vocabulary mastery and word identification, characters and spelling were the next most important skills. Mobile applications were generally able to provide learners with feedback on achievement, support in record-keeping, and algorithms to make intelligent choices in repeating needed exercises[49]. Therefore, many AR-related past studies in language learning selected vocabulary as the language focus. Nevertheless, researchers should also consider the incorporation of other language skills in the AR environment and explore the potential of AR usage to develop 
higher-order cognitive skills. The creation of AR applications using a language other than English was also desired.

\section{Conclusion}

This paper presented a systematic review of utilising AR applications in language learning within the span of 10 years, from 2010 to 2020 . A total of 29 papers were evaluated, encompassing a diverse range of educational levels, research designs, language skills, and AR types specifically used in language learning classrooms. Based on the analysis, the number of researches in this field has increased from 2016 onwards, with the preferred learner types comprising undergraduates and primary school students. Most studies employed a mixed-method research design and questionnaires as the most common data-collection method, followed by pre and post-tests, and interviews. Although eight of the studies did not mention theories, the process of developing AR applications was described. Game-based or gamification principles were also among the frequently applied theories in the reviewed papers. Most of the studies also used vocabulary as the skill to be integrated with AR applications, followed by orthography or spelling, and pronunciation.

From this review, the apparent gaps in AR applications, specifically in language learning, could be identified. Many studies ([25, 26, 48]) focused on the lexical level of language learning requiring identification, memorisation, and lower-level cognitive skills. More researches should be conducted on the feasibility of AR usage applications in more complex language skills, such as critical reading, contextual written language, and interpreting relevant information. Future researches should also focus on the 'how' and 'why' of AR technology effectiveness. For example, a qualitative study should be implemented to uncover AR technology-related phenomenon regarding cognitive processes, knowledge building, and collaboration.

Additionally, longitudinal studies should be conducted to understand the gradual development of knowledge and skills [21]. The reported findings indicated the effective use of AR technology in boosting learning motivations and performance, but further examination was required on whether the aspect of novelty influenced the implementation of AR applications. The researcher could also focus on advancing the current theories or introducing new theories related to educational technologies. This study intended to enlighten future researchers on the lacking areas and strategies for more value-added AR research, specifically in language learning.

\section{$7 \quad$ References}

[1] Roe, D. (2020) Why AR and VR Usage Is Expected to Grow in 2020. https://www.cmsw ire.com/digital-workplace/why-ar-and-vr-usage-is-expected-to-grow-in-2020/ (accessed 5 July 2020, 2020).

[2] Masrom, M., Nadzari, A. S., and Zakaria, S. A., (2016) Implementation of Mobile Learning Apps in Malaysia Higher Education Institutions, in 4th Global Summit on Education GSE 2016, Kuala Lumpur, Malaysia, 2016, pp. 268-276. 
[3] Murugan, A., Sai, G. T. B., and Lin, A. L. W., (2017). Technological Readiness of UiTM students in Using Mobile Phones in The English Language Classroom, Malaysian Online Journal of Educational Technology, vol. 5, no. 2, pp. 34-50.doi. [Online]. Available: http://www.mojet.net/article/getpdf/162.

[4] Persson, V. and Nouri, J., (2018). A Systematic Review of Second Language Learning with Mobile Technologies, International Journal of Emerging Technologies in Learning (iJET), vol. 13, no. 02, https://doi.org/10.3991/ijet.v13i02.8094.

[5] Deris, F. D., Koon, R. T. H., and Salam, A. R., (2015). Virtual Communities in an Online English Language Learning Forum, International Education Studies, vol. 8, no. 13, https:// doi.org/10.5539/ies.v8n13p79.

[6] Tan, K.-E., (2017). Using online discussion forums to support learning of paraphrasing, British Journal of Educational Technology, vol. 48, no. 6, pp. 1239-1249.doi: https://doi. org/10.1111/bjet.12491.

[7] Ismail, N., Hussin, S., and Aboswider, R. O. S., (2019). Examining the Mechanisms Utilized by CML Web-Logging Instructors in ESL Classroom: A Case Study, AJELP: The Asian Journal of English Language and Pedagogy, vol. 7, no. 2, pp. 31-39.doi: https://doi. org/10.37134/ajelp.vol7.2.4.2019.

[8] Balakrishnan, V., Liew, T. K., and Pourgholaminejad, S., (2015). Fun learning with Edooware - A social media enabled tool, Computers \& Education, vol. 80, pp. 39-47.doi: https://doi.org/10.1016/j.compedu.2014.08.008.

[9] Omar, H., Amin Embi, M., and Md Yunus, M., (2012). ESL Learners' Interaction in an Online Discussion via Facebook, Asian Social Science, vol. 8, no. 11, https://doi.org/10. 5539/ass.v8n11p67.

[10] Ahmed, B. E. S., (2020). Social Media in Teaching of Languages, International Journal of Emerging Technologies in Learning (iJET), vol. 15, no. 12, https://doi.org/10.3991/ijet.v $15 \mathrm{i} 12.12645$.

[11] Hussain, S. Y. S., Tan, W. H., and Idris, M. Z., (2014). Digital Game-Based Learning for Remedial Mathematics Students: A New Teaching and Learning Approach in Malaysia, International Journal of Multimedia and Ubiquitous Engineering, vol. 9, no. 11, pp. 325338.doi: https://doi.org/10.14257/ijmue.2014.9.11.32.

[12] Kamaruzaman, N. N. and Jomhari, N., (2013), Digital Game-Based Learning for Low Functioning Autism Children in Learning Al-Quran, presented at the 2013 Taibah University International Conference on Advances in Information Technology for the Holy Quran and Its Sciences. https://doi.org/10.1109/nooric.2013.46

[13] Tazouti, Y., Boulaknadel, S., and Fakhri, Y., (2019). JeuTICE: An Arabic Serious Game to Enhance Mathematics Skills of Young Children, International Journal of Emerging Technologies in Learning (iJET), vol. 14, no. 22, https://doi.org/10.3991/ijet.v14i22.11119.

[14] Das, P., Zhu, M. o., McLaughlin, L., Bilgrami, Z., and Milanaik, R. L., (2017). Augmented Reality Video Games: New Possibilities and Implications for Children and Adolescents, Multimodal Technologies and Interaction, vol. 1, no. 2, pp. 1-0.doi: https://doi.org/10. 3390/mti1020008.

[15] Majid, S. N. A., Ismail, R., Kassim, H., Kassim, A., and Bakar, A. H. A., (2018) Students' Perception in Using Virtual Reality Device in English Classroom, in the 12th Malaysia International Conference on English Language Teaching (MICELT) 2018 Serdang, Selangor, Malaysia, 2018, pp. 373-381.

[16] Cheng, J., Wang, Y., Tjondronegoro, D., and Song, W., (2018). Construction of Interactive Teaching System for Course of Mechanical Drawing Based on Mobile Augmented Reality Technology, International Journal of Emerging Technologies in Learning (iJET), vol. 13, no. 02, https://doi.org/10.3991/ijet.v13i02.7847. 
[17] Azuma, R. T., (1997). A Survey of Augmented Reality, Presence, vol. 6, no. 4, pp. 355385.doi.

[18] Cheng, K.-H., (2017). Exploring Parents' Conceptions of Augmented Reality Learning and Approaches to Learning by Augmented Reality With Their Children, Journal of Educational Computing Research, vol. 55, no. 6, pp. 820-843.doi: https://doi.org/10.1177/07356 33116686082 .

[19] Johnson, L., Levine, A., Smith, R., and Stone, S., "The 2010 Horizon Report," Austin, Texas, 2010. [Online]. Available: https://library.educause.edu/-/media/files/library/2010/1 lcsd5810-pdf.pdf

[20] Akçayır, M. and Akçayır, G., (2017). Advantages and challenges associated with augmented reality for education: A systematic review of the literature, Educational Research Review, vol. 20, pp. 1-11.doi: https://doi.org/10.1016/j.edurev.2016.11.002.

[21] Bacca, J., Baldiris, S., Fabregat, R., Graf, S., and Kinshuk, (2014). Augmented Reality Trends in Education: A Systematic Review of Research and Applications, Educational Technology \& Society, vol. 17, no. 4, pp. 133-149.doi. [Online]. Available: http://disde. minedu.gob.pe/bitstream/handle/123456789/5029/Augmented\%20Reality\%20Trends\%20i n\%20Education $\% 20 \mathrm{~A} \% 20$ Systematic\%20Review\%20 of $\% 20$ Research\%20and\%20Applica tions.pdf?sequence=1\&isAllowed=y. https://doi.org/10.14742/ajet.4182

[22] Radu, I., (2012) Why Should My Students Use AR? A Comparative Review of the Educational Impacts of Augmented-Reality, in IEEE International Symposium on Mixed and Augmented Reality 2012 Atlanta, Georgia, 5 - 8 November 2012 2012, 2012. https://doi. org/10.1109/ismar.2012.6402590

[23] Diegmann, P., Schmidt-Kraepelin, M., Van den Eynden, S., and Basten, D., (2015) Benefits of Augmented Reality in Educational Environments - A Systematic Literature Review, in Proceedings of the 12th International Conference on Information Systems (WI 2015), Osnabrück, O. Thomas and F. Teuteberg, Eds., 2015, pp. 1542-1556.

[24] Saidin, N. F., Abd Halim, N. D., and Yahaya, N., (2015). A Review of Research on Augmented Reality in Education: Advantages and Applications, International Education Studies, vol. 8, no. 13, https://doi.org/10.5539/ies.v8n13p1.

[25] Che Dalim, C. S., Sunar, M. S., Dey, A., and Billinghurst, M., (2020). Using augmented reality with speech input for non-native children's language learning, International Journal of Human-Computer Studies, vol. 134, pp. 44-64.doi: https://doi.org/10.1016/j.ijhcs.2019 .10 .002 .

[26] Fung, K.-Y., Fung, K.-C., Sally, D., and Wan, W.-Y., (2019) Augmented Reality and 3D Model for Children Chinese Character Recognition - Hong Kong Primary School Education, in 27th International Conference on Computers in Education, Taiwan, M. e. a. Chang, Ed., 2019, Taiwan: Asia-Pacific Society for Computers in Education, 2019, pp. 673-678.

[27] Perry, B., (2015). Gamifying French Language Learning: A Case Study Examining a Quest-based, Augmented Reality Mobile Learning-tool, Procedia - Social and Behavioural Sciences, vol. 174, pp. 2308-2315.doi: https://doi.org/10.1016/j.sbspro.2015.01.892.

[28] Lee, S.-M. and Park, M., (2019). Reconceptualization of the context in language learning with a location-based AR app, Computer Assisted Language Learning, pp. 1-24.doi: https ://doi.org/10.1080/09588221.2019.1602545.

[29] Yang, S. and Mei, B., (2018). Understanding learners' use of augmented reality in language learning: insights from a case study, Journal of Education for Teaching, vol. 44, no. 4, pp. 511-513.doi: https://doi.org/10.1080/02607476.2018.1450937.

[30] Herpich, F., Nunes, F. B., Petri, G., and Tarouco, L. M. R., (2019). How Mobile Augmented Reality Is Applied in Education? A Systematic Literature Review, Creative Education, vol. 10, no. 07, pp. 1589-1627.doi: https://doi.org/10.4236/ce.2019.107115. 
[31] Sirakaya, M. and Sirakaya, D. A., (2018). Trends in Educational Augmented Reality Studies: A Systematic Review, Malaysian Online Journal of Educational Technology, vol. 6, no. 2, pp. 60-74.doi: https://doi.org/10.17220/mojet.2018.04.005.

[32] Moher, D. et al., (2015). Preferred reporting items for systematic review and meta-analysis protocols (PRISMA-P) 2015 statement, Syst Rev, vol. 4, p. 1.doi: https://doi.org/10.1186/ 2046-4053-4-1.

[33] [33] Bar-Ilan, J., (2018). Tale of Three Databases: The Implication of Coverage Demonstrated for a Sample Query, Frontiers in Research Metrics and Analytics, vol. 3, https://doi. org/10.3389/frma.2018.00006.

[34] Luor, T., Johanson, R. E., Lu, H.-P., and Wu, L.-1., (2008). Trends and lacunae for future computer assisted learning (CAL) research: An assessment of the literature in SSCI journals from 1998-2006, Journal of the American Society for Information Science and Technology, vol. 59, no. 8, pp. 1313-1320.doi: https://doi.org/10.1002/asi.20836.

[35] Creswell, J. W. and Creswell, J. D., 2018, Research Design: Qualitative, Quantitative, and Mixed Methods Approaches, Fifth ed. Los Angeles: SAGE.

[36] Recchia, C. (2018) Augmented Reality Marketing: Three Companies That Have Done It Best. https://www.forbes.com/sites/forbesagencycouncil/2018/03/01/augmented-reality-ma rketing-three-companies-that-have-done-it-best/\#173496912dc8 (accessed 5 July 2020, 2020).

[37] Wu, H.-K., Lee, S. W.-Y., Chang, H.-Y., and Liang, J.-C., (2013). Current status, opportunities and challenges of augmented reality in education, Computers \& Education, vol. 62, pp. 41-49.doi: https://doi.org/10.1016/j.compedu.2012.10.024.

[38] Lai, J. W. M. and Bower, M., (2019).How is the use of technology in education evaluated? A systematic review, Computers \& Education, vol. 133, pp. 27-42.doi: https://doi.org/10. 1016/j.compedu.2019.01.010.

[39] Mei, B. and Yang, S., (2019). Nurturing Environmental Education at the Tertiary Education Level in China: Can Mobile Augmented Reality and Gamification Help?, Sustainability, vol. 11, no. 16, https://doi.org/10.3390/su11164292.

[40] Cheng, K.-H. and Tsai, C.-C., (2013). Affordances of Augmented Reality in Science Learning: Suggestions for Future Research, Journal of Science Education and Technology, vol. 22, no. 4, pp. 449-462.doi: https://doi.org/10.1007/s10956-012-9405-9.

[41] Maas, M. J. and Hughes, J. M., (2020). Virtual, augmented and mixed reality in K-12 education: a review of the literature, Technology, Pedagogy and Education, vol. 29, no. 2, pp. 231-249.doi: https://doi.org/10.1080/1475939x.2020.1737210.

[42] Hew, K. F., Lan, M., Tang, Y., Jia, C., and Lo, C. K., (2019). Where is the "theory" within the field of educational technology research?, British Journal of Educational Technology, vol. 50, no. 3, pp. 956-971.doi: https://doi.org/10.1111/bjet.12770.

[43] Warschauer, M., Park, Y., and Walker, R., (2011). Transforming digital reading with visual-syntactic text formatting, The JALT CALL Journal, vol. 7, no. 3, pp. 255-270.doi: https ://doi.org/10.29140/jaltcall.v7n3.121.

[44] Huang, H.-M., Rauch, U., and Liaw, S.-S., (2010). Investigating learners' attitudes toward virtual reality learning environments: Based on a constructivist approach, Computers \& Education, vol. 55, no. 3, pp. 1171-1182.doi: https://doi.org/10.1016/j.compedu.2010.05. $\underline{014}$.

[45] Cheng, J. C. P., Chen, K., and Chen, W., (2017), Comparison of Marker-Based and Markerless AR: A Case Study of An Indoor Decoration System, presented at the Lean and Computing in Construction Congress - Volume 1: Proceedings of the Joint Conference on Computing in Construction. https://doi.org/10.24928/jc3-2017/0231 
[46] Arici, F., Yildirim, P., Caliklar, Ş., and Yilmaz, R. M., (2019). Research trends in the use of augmented reality in science education: Content and bibliometric mapping analysis, Computers \& Education, vol. 142, https://doi.org/10.1016/j.compedu.2019.103647.

[47] Davis, F. D., (1989). Perceived Usefulness, Perceived Ease of Use, and User Acceptance of Information Technology, MIS Quarterly, vol. 13, no. 3, pp. 319-340.doi. [Online]. Available: http://links.jstor.org/sici?sici=0276-7783\%28198909\%2913\%3A3\%3C319\%3A PUPEOU\%3E2.0.CO\%3B2-E. https://doi.org/10.2307/249008

[48] Palaigeorgiou, G., Griva, E., Raftogianni, P.-D., and Toronidou, M., (2018) Improving Vocabulary Acquisition in a Second/Foreign Language with a Mixed Reality Environment and a Drone, in ECEL 2018 17th European Conference on e-Learning, 2018: Academic Conferences and Publishing limited, pp. 447-455.

[49] Burston, J., (2011). Realizing the Potential of Mobile Phone Technology for Language Learning, International Association for Language Learning Technology, vol. 41, no. 2, pp. 56-71.doi. https://doi.org/10.17161/iallt.v41i2.8490

\section{Authors}

Siti Norzaimalina Abd Majid received her B.Ed. degree in Teaching English as Second Language (TESL) from National University of Malaysia, Bangi, Selangor, Malaysia (2009) and M. Arts degree in English Language Studies (ELS) from the same university in 2011. She works as an English lecturer, teaching ESL and EFL students at Universiti Malaysia Pahang, Pahang, Malaysia. Currently, she is pursuing $\mathrm{PhD}$ at Universiti Teknologi Malaysia, Johor, Malaysia.

Abdul Rahim Salam received his B.Ed degree in Teaching English as Second Language (TESL) from Universiti Malaya, Kuala Lumpur. He obtained his Masters and PhD (TESL) from Universiti Teknologi Malaysia. He is currently an Assoc. Professor Dr. at Language Academy, Faculty of Social Sciences and Humanities, UTM. He has been involved in teaching and researching CALL and CMC. He is actively supervising $\mathrm{PhD}$ research students especially in the area related to Language Learning Technology and Communication.

Article submitted 2020-07-24. Resubmitted 2020-12-15. Final acceptance 2020-12-16. Final version published as submitted by the authors. 